\title{
Article \\ Surface Alloying and Improved Property of Nb on TC4 Induced by High Current Pulsed Electron Beam
}

\author{
Xueze Du ${ }^{1}$, Nana Tian ${ }^{1}$, Conglin Zhang ${ }^{2, *}$, Peng Lyu ${ }^{1}$, Jie Cai ${ }^{3}$ and Qingfeng Guan ${ }^{1, *}$ \\ 1 School of Materials Science and Engineering, Jiangsu University, Zhenjiang 212013, China; \\ xueze_du@163.com (X.D.); tianna118@163.com (N.T.); lvp@ujs.edu.cn (P.L.) \\ 2 School of Materials Science and Engineering, Yancheng Institute of Technology, Yancheng 224051, China \\ 3 Engineering Institute of Advanced Manufacturing and Modern Equipment Technology, Jiangsu University, \\ Zhenjiang 212013, China; caijie@ujs.edu.cn \\ * Correspondence: conglin_zhang@126.com (C.Z.); guanqf@ujs.edu.cn (Q.G.); Tel.: +86-157-5101-0315 (C.Z.); \\ +86-138-5290-4936 (Q.G)
}

Citation: Du, X.; Tian, N.; Zhang, C.; Lyu, P.; Cai, J.; Guan, Q. Surface Alloying and Improved Property of $\mathrm{Nb}$ on TC4 Induced by High Current Pulsed Electron Beam. Nanomaterials 2021, 11, 2906. https://doi.org/ $10.3390 /$ nano11112906

Academic Editors: Zulfiqar Ahmad Khan and Jordi Sort

Received: 22 September 2021

Accepted: 26 October 2021

Published: 29 October 2021

Publisher's Note: MDPI stays neutral with regard to jurisdictional claims in published maps and institutional affiliations.

\begin{abstract}
In this paper, an Nb alloying layer on a TC4 alloy was fabricated by using high-current pulsed electron beam (HCPEB) irradiation to improve surface performance. X-ray diffraction (XRD), optical microscopy (OM), laser surface microscope (LSM), scanning electron microscopy (SEM) and transmission electron microscopy (TEM) were used to characterize the phase composition and microstructure of the surface layer. The microhardness, wear tests and corrosion resistance were also examined. The results show that after HCPEB alloying, a Nb-alloyed layer was formed with about $3.6 \mu \mathrm{m}$ in thickness on the surface of the sample, which was mainly composed of $\alpha^{\prime}$-Ti martensite, $\beta$-Ti equiaxial crystals, and $\mathrm{NbTi}_{4}$ particles. After HCPEB irradiation, the surface hardness, wear resistance and corrosion resistance of $\mathrm{Nb}$ alloying layer on $\mathrm{TC} 4$ alloy were improved compared to the initial samples.
\end{abstract}

Keywords: high-current pulsed electron beam (HCPEB); TC4 alloy; Nb alloying; microhardness; wear resistance; corrosion resistance

\section{Introduction}

The TC4 alloy (Ti6Al4V) is widely used in aerospace, military, biomedical and chemical industries because of its good corrosion resistance, high specific strength, stable mediumtemperature performance and high biocompatibility [1,2]. However, the TC4 alloy has some unsolved surface problems, including low hardness and poor wear resistance. In addition, TC4 has poor corrosion resistance in some special media (including reducing acid and $\mathrm{NaCl}$ solution), which mean it can barely meet the application requirements under some circumstances [3,4]. In order to ensure that the TC4 alloy can give full play to its excellent performance under harsh usage conditions, many researchers have employed the alloying method to treat TC4 alloys by adopting surface treatment techniques [5-7]. Despite this, the surface technologies such as vapor deposition, laser surface technology, and ion bean injection have been used widely in the titanium alloys, but some issues including high cost, low efficiency and complex operation remain unsolved [8].

As a new and potential surface alloying technology, HCPEB has been widely studied by scholars for years $[9,10]$. It is characterized by a large beam spot, strong beam current and short pulse width. The surface layer of the material is injected with the high beam energy to make the surface alloying elements and matrix undergo ultra-rapid heating and cooling at the same time, which leads to the fusion of the alloying elements and matrix and the forming of an alloying layer on the surface of the matrix [11-13]. In addition, HCPEB cannot only refine the surface layer of the matrix grain and homogenize the surface composition, but it can also solve the problem of weak interface adhesion between the matrix and the coating by realizing the metallurgical bonding, which is usually unattainable 
with conventional methods. Many researchers have used HCPEB technology to study surface alloying. For example, Rotshtein [14] adopted an electron beam to alloy Cu onto a 316 stainless steel surface. After that, Zhang [15] conducted a Cr surface alloying treatment on Ni surface, and Yang [16] adopted $\mathrm{Cu}$ as an alloying element on a nickel substrate by HCPEB. In the previous works, whether the alloying element could be successfully alloyed depended on the formation of a solid solution or an amorphous phase between the dissolved and the matrix elements. However, $\mathrm{Nb}$ is an element with high melting point and good corrosion resistance, which can be easily dissolved in the TC4 alloy, increasing the passivation tendency of the surface and improving the corrosion resistance of TC4. This has important theoretical and practical significance for the service safety of ship parts such as flanges, threads and deep vertical pipes, which need to be served in the marine environment.

In this paper, $\mathrm{HCPEB}$ irradiation was used to conduct $\mathrm{Nb}$ alloying treatment on a TC4 surface. The influence of the surface element distribution, phase composition and microstructure on the surface properties of the alloying layer under different irradiation was investigated. TC4-Nb surface alloying process and performance improvement mechanisms under the action of HCPEB were discussed.

\section{Experimental}

The annealed industrial TC4 alloy bar was used as the matrix material, and the corresponding chemical composition (wt \%) was: Al 6.00\%, V 4.30\%, Fe 0.16\%, C 0.01\%, $\mathrm{N} 0.01 \%$, O $0.18 \%, \mathrm{H} 0.004 \%$, and the balanced Ti. TC4 alloy bars were machined into cylinder with a diameter of $10 \mathrm{~mm}$ and thickness of $5 \mathrm{~mm}$, and then they were grounded, mechanical polished, and cleaned ultrasonically in acetone, respectively. The purity of $99.9 \% \mathrm{Nb}$ powder (400 mesh, particle size about $30 \sim 40 \mu \mathrm{m}$ ) was selected as alloying material. The pretreatment is to mix $10 \mathrm{~g} \mathrm{Nb}$ powder and binder $(100 \mathrm{~mL}$, nitrocelluar varnish + diluent, mass ratio 1:2) evenly, then spray it on the mechanically polished TC4 alloy surface with an air-pressurized spraying gun, then dry the sample in a vacuum drying oven at room temperature for $5 \mathrm{~h}$, and the coating thickness measured with a vernier caliper is about $150 \mu \mathrm{m}$. Then the "HOPE-I" type HCPEB equipment (DLUT, DL, $\mathrm{CHN}$ ) was adopted to conduct surface alloying treatment on the pretreated TC4 alloy with 20, 30 and 40 times of pulses. The process parameters of the electron beam are: accelerating voltage $27 \mathrm{kV}$, energy density of $4 \mathrm{~J} / \mathrm{cm}^{2}$, a vacuum degree $5.0 \times 10^{-3} \mathrm{~Pa}$, a pulse width of $1.5 \mu \mathrm{s}$, a beam spot diameter $60 \mathrm{~mm}$, and a pulse interval of $10 \mathrm{~s}$. For more information on the HCPEB system, readers can refer to Ref [17]. Hereafter, the Nb powder coated TC4 alloy after HCPEB irradiation is referred to as an $\mathrm{Nb}$-alloyed sample.

Rigaku D/Max-2500/pc X-ray diffractometer (XRD) (Panalytical, NL)with parameters of $\mathrm{CuK} \alpha$ radiation was used to analyze the phase composition of the alloying surface. The morphology of the alloying surface was observed by an ObserverZ1m type Zeiss metallographic microscope (OM), laser confocal microscope (LSM) (OLS4100, JPN), and a scanning electron microscope (SEM) (JEOL JSM-7001F field emission, JPN). The microstructure of the alloying layer was studied bytransmission electron microscopy (TEM) (JEOL-2100, JPN). The sample used for TEM characterization was manually ground on a single surface (the opposite of the irradiated surface), and then the ion mill was thinned to transparency. The microhardness of the sample was measured by microhardness tester (HV-1000, REEDEA, $\mathrm{CHN}$ ), a load of $0.245 \mathrm{~N}$ (25 g) of $15 \mathrm{~s}$ was applied to the surface, seven test points were taken from each sample, but the maximum and minimum values were removed to reduce random error. In addition, a 20 min friction and wear test was carried out on an SFT-2M type ball in a testing machine at room temperature, which selected a GCr15 ball ( $\phi 6 \mathrm{~mm})$ as grinding materials, and the hardness, the running load, the speed, the turning radius were $62 \mathrm{HRC}, 5 \mathrm{~N}, 300 \mathrm{r} / \mathrm{min}, 2 \mathrm{~mm}$, respectively. The quality of the sample before and after grinding was measured by an electronic balance. In the electrochemical corrosion experiment, a electrochemical measurement system (CHI760C, Bee Cave, TX, USA) was used, which was the traditional three-electrode system. The $3.5 \% \mathrm{NaCl}$ solution was a 
corrosive medium, the platinum net and saturated calomel electrode (SCE) were auxiliary and reference electrodes.

\section{Results and Discussion}

\subsection{Phase Identification}

Figure 1 shows the X-ray diffraction pattern of initial TC4 alloy and $\mathrm{Nb}$-alloyed samples. It can be seen from Figure 1a that the TC4 alloy is composed of $\alpha$ and $\beta$ phases. Compared to the original sample (TC4), the location of the $\alpha$ and $\beta$ phases diffraction peaks showed no obvious difference after 20-pulsed irradiation. Furthermore, the $\alpha^{\prime}$ and $\alpha$ phases have the same crystal structure (hcp) and are only slightly different in lattice parameters [18]; they cannot be distinguished by the location of diffraction peak (Figure 1a). But according to related literature [3], the rapid heating and cooling of the high energy beam can make the TC4 alloy undergo martensitic transformation and form $\alpha^{\prime}$ martensitic phase due to HCPEB irradiation. Therefore, the diffraction peak at the $\alpha$ phase position should be labeled as $\alpha^{\prime}$ phase after alloying, which will be confirmed by TEM analysis in the following. According to the TEM results, the equiaxed $\beta$-Ti grains should be formed after HCPEB irradiation, and the $\beta$ diffraction peak should be seen in the XRD results, so we hypothesized that the $\beta$ phase should coincide with the $\alpha^{\prime}$ phase. Besides, the (101) diffraction peak of $\alpha^{\prime}$ phase is widened after HCPEB irradiation, as shown in Figure 1b, indicating the surface grain refinement and lattice distortion increment.
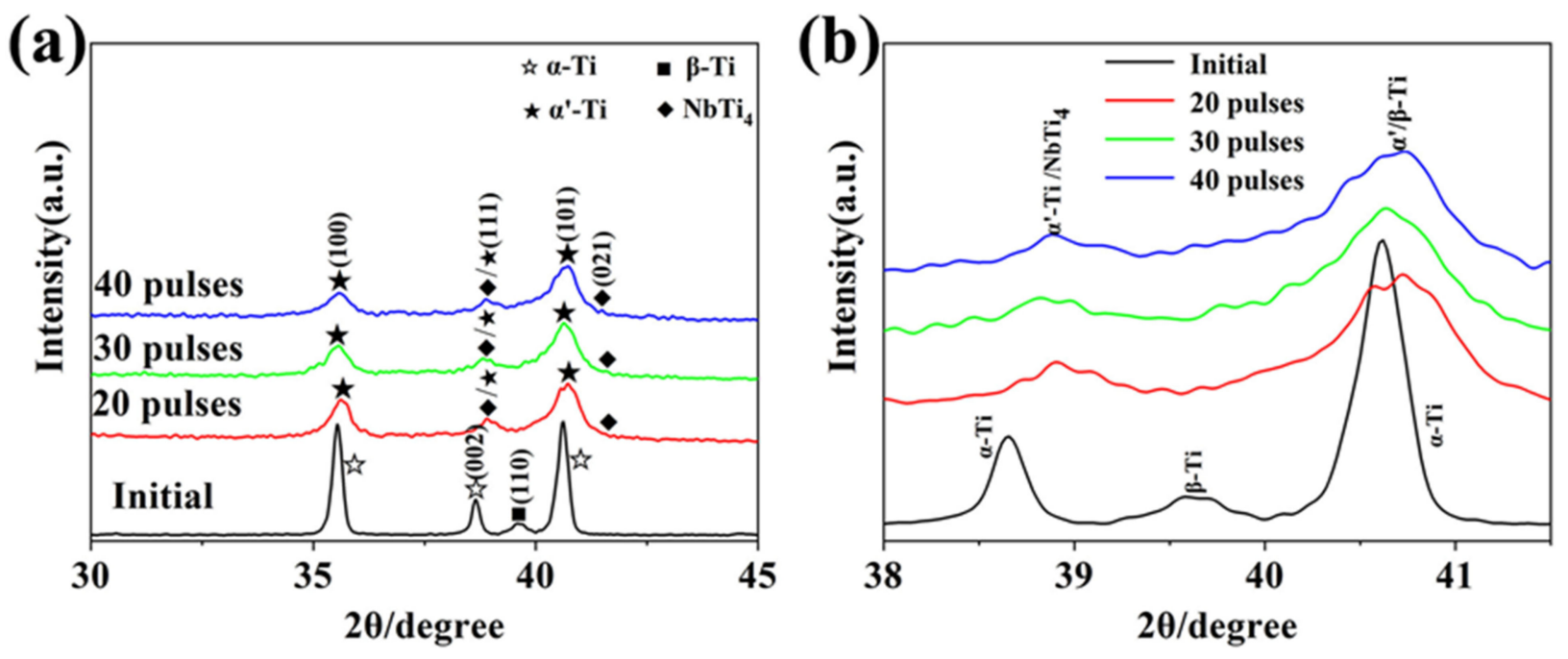

Figure 1. XRD analysis results of the samples before and after $\mathrm{Nb}$ alloying. (a) XRD patterns; (b) Magnified picture of the diffraction peaks near $40^{\circ}$.

It is worth noting that the $\mathrm{NbTi}_{4}$ phase was found on the $\mathrm{Nb}$-alloyed surfaces, which proves that the $\mathrm{Nb}$ powders were dissolved into the Ti6Al4V substrate. It confirmed that the surface $\mathrm{Nb}$-alloying on TC4 alloy is successful with HCPEB irradiation.

\subsection{Surface Topography}

Figure 2 gives surface morphology, crater density and surface roughness of the initial TC4 and Nb-alloyed samples. The metallographic images of annealed TC4 alloy reveals that the original sample is consists of $\alpha$ (white) and $\beta$ (black) phases, as shown in Figure 2a. The metallographic morphology (uncorroded) of 20-, 30- and 40-pulsed irradiation samples are shown in Figure $2 \mathrm{~b}-\mathrm{d}$. The uneven distribution of craters were formed on the irradiated surface, which is consistent with many previous research results $[19,20]$. Cratering is the most typical morphology characteristic of HCPEB irradiated metal surface, and it is easy to nucleated in the local defects zone, some inclusions or uneven composition of the subsurface layer of the material. Initially, the subsurface layer of the material melts 
due to the accumulation of energy under HCPEB irradiation. Afterwards the volume of the melted liquid expands rapidly, followed by an eruption from the surface, and then solidifies quickly to form craters $[21,22]$. The crater density curve indicated that the number of craters decreases gradually with the increase of exposure pulses, as showed in Figure 2e, and the size of craters also decreased. As a result, the surface becomes smooth and uniform. Figure $2 \mathrm{f}$ displays the roughness histogram of the sample surface measured by a laser scanning surface microscope after HCPEB irradiation. The surface roughness decreased when the irradiation pulses increased. This is mainly because of the "self-purification" effect of HCPEB irradiation. This can be explained by the fact that a reduction in the number and size of the crater and subsequent fusion of the surface will cause a gradual disappearance in the previously visible formed craters.
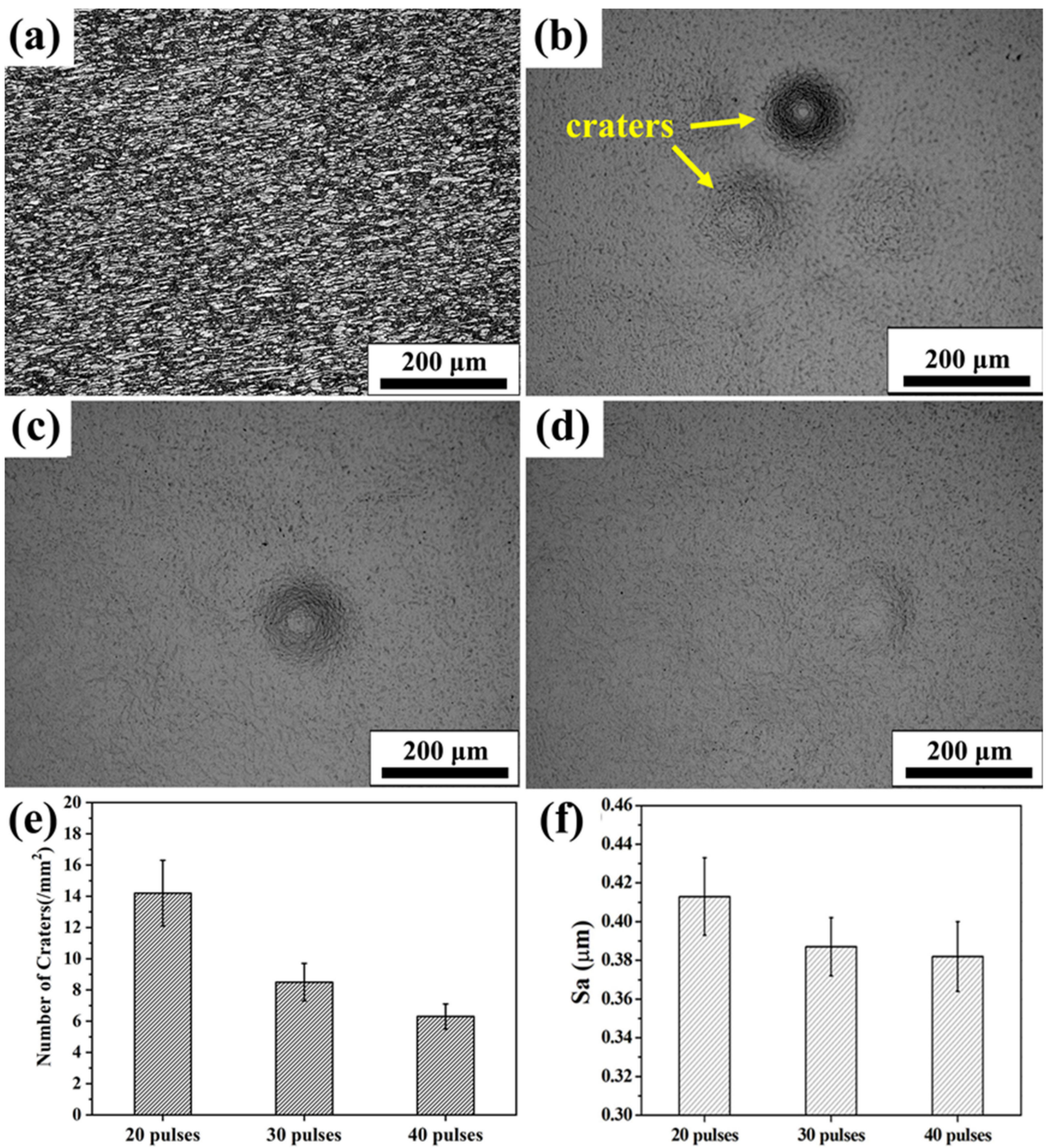

Figure 2. OM images, crater density and surface roughness of initial and Nb-alloyed samples. (a) Initial; (b) 20 pulses; (c) 30 pulses; (d) 40 pulses; (e) Number of craters; (f) Surface roughness.

The cross-section morphology and EDS line analysis results of 40-pulsed samples are shown in Figure 3. The surface can be categorized into three distinct layers: the alloying layer, the heat affected zone and the matrix. This is basically consistent with the remelting 
layer of titanium alloy treated by HCPEB irradiation [23]. The EDS line analysis of the horizontal black line revealed that $\mathrm{Nb}$ elements only exist within the range of $3.6 \mu \mathrm{m}$ under the surface. This implied that the Nb elements dissolved into the TC4 matrix to form a $\mathrm{Nb}$-rich alloying layer on the topmost surface after the irradiation. Underneath is the heataffected zone with the thickness of about $5.7 \mu \mathrm{m}$, and its microstructure is homogeneous with fine grains compared to the matrix. The substrate was located below the heat-affected zone and was not affected by HCPEB irradiation.

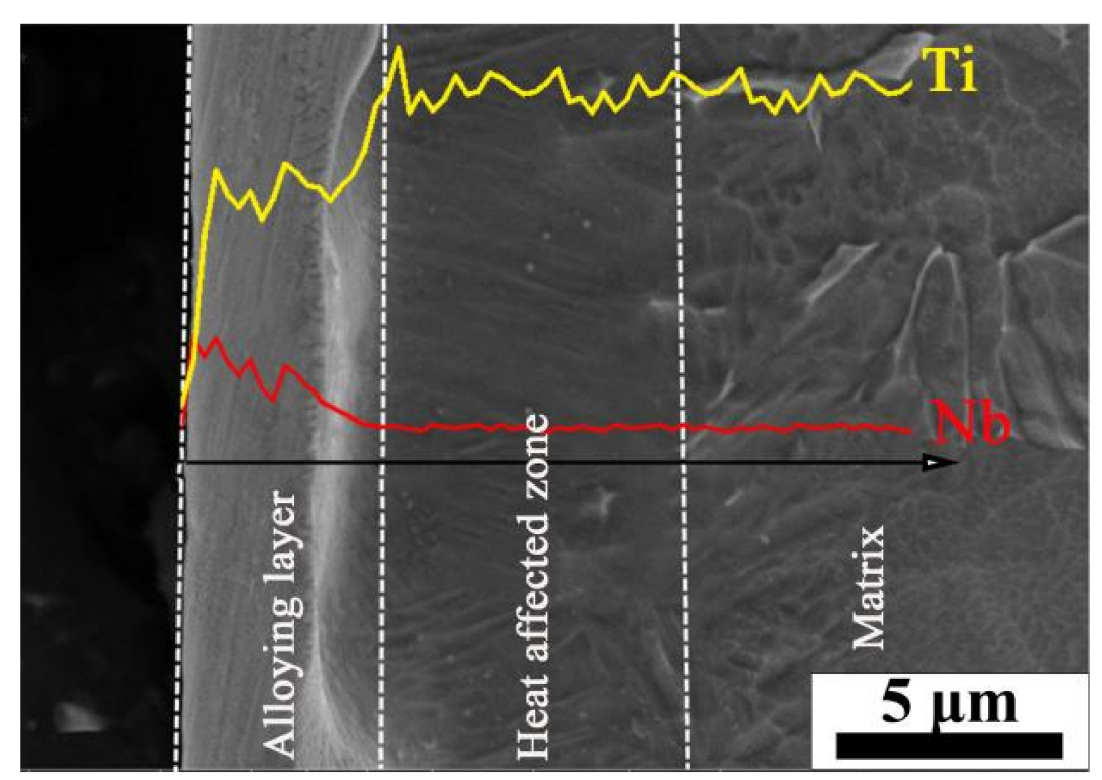

Figure 3. Cross-sectional morphology and EDS analysis of the TC4-Nb samples after 40-pulsed HCPEB irradiation.

Figure 4 shows the SEM images and EDS results of the $\mathrm{Nb}$-alloyed samples. After 20 pulses of irradiation, no obvious grains can be observed, as shown in Figure 4a. EDS analysis shows that the white area in the red box consisted of the remaining $\mathrm{Nb}, \mathrm{Ti}, \mathrm{Al}$ and $\mathrm{V}$ elements. It suggested that the $\mathrm{Nb}$ element has not been completely melted into the matrix (Figure 4a). The surface of the samples became even, smooth and uniform when the number of pulses increased from 30 to 40 (Figure $4 b, c)$, and no $\mathrm{Nb}$ segregation area was found. The EDS results of the surface for 40-pulsed sample (red box mark in Figure 4c) shows that the $\mathrm{Nb}$ content is about $5.0 \mathrm{wt} . \%$, indicating that $\mathrm{Nb}$ powder have been melted completely and distributed on the surface with the increase of irradiation pulses.

Figure 5 illustrates the magnified image of the TC4-Nb surface morphology after 40-pulsed irradiation. From Figure $5 \mathrm{a}$, the $\mathrm{Nb}$-alloyed sample surface consists of equiaxial grains with the size ranging from 1 to $5 \mu \mathrm{m}$. Each single individual grain is clearly visible and the grains resulted in an uneven surface. Previous studies demonstrated that the surface morphology was due to the anisotropy of the thermal stress during irradiation, which resulted in the deformation of grains with different orientations [22,24]. The surface morphology at a higher magnification is shown in Figure 5b. It was found that the lamellar structure appears inside the $\beta$-phase grain, which was identified as $\alpha^{\prime}$ martensite phase according to the XRD results in Figure 1. The formation of $\alpha^{\prime}$ phase is due to the rapid solidification of the electron beam and the stress field induced by it, which is consistent with the results in the literature $[3,25,26]$. 


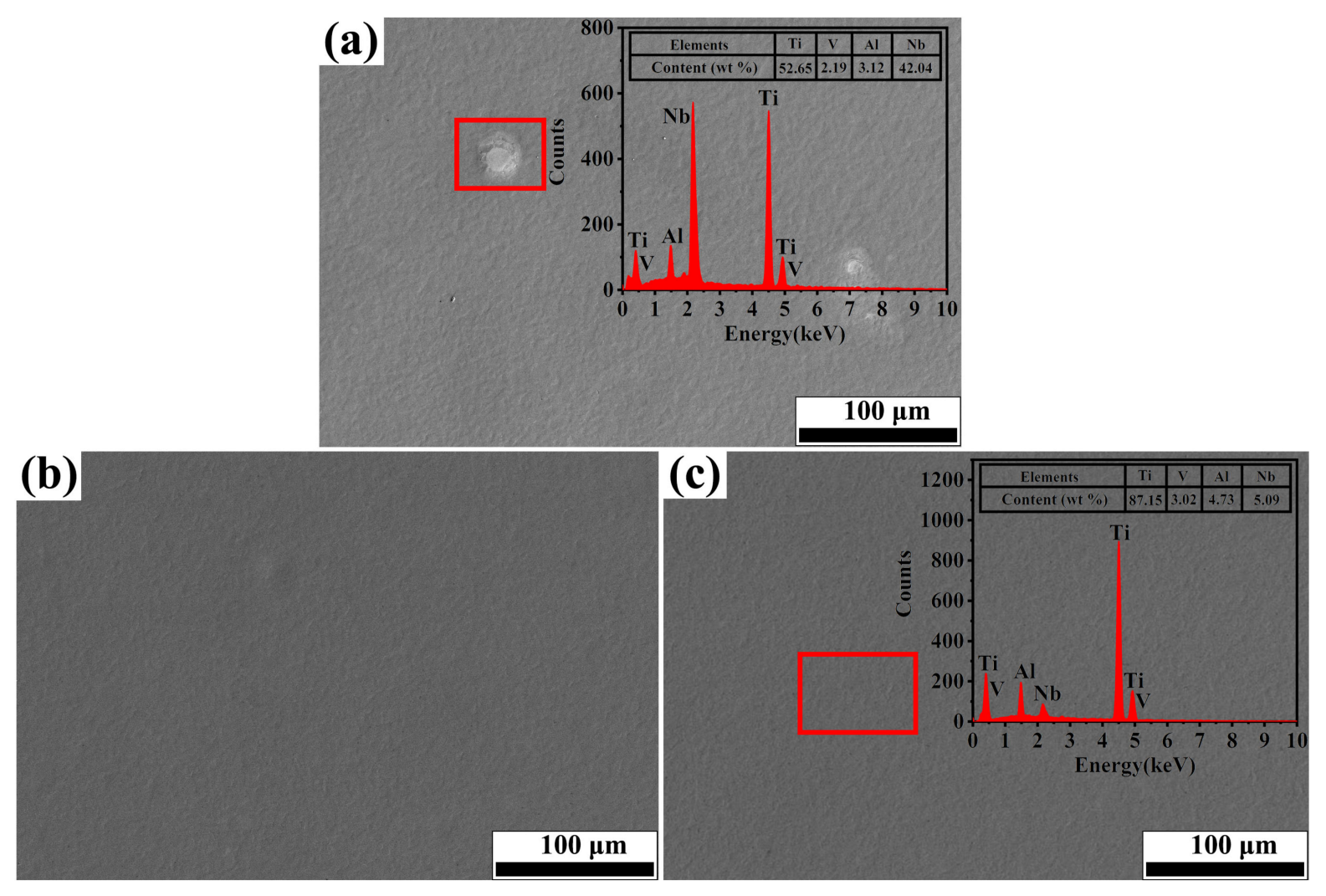

Figure 4. SEM morphology of samples after HCPEB irradiation. (a) 20 pulses; (b) 30 pulses; (c) 40 pulses.

Figure $5 c-f$ show the TEM images of the $\mathrm{Nb}$-alloyed samples. Figure $5 \mathrm{c}$ gives the lath martensite structure, which was proven to be martensite $\alpha^{\prime}$ phase by selected area electron diffraction pattern (SAED). And the equiaxed grains with the width of 50 and $100 \mathrm{~nm}$ were found as $\beta$-Ti phase. In fact, a $\beta-\alpha^{\prime}$ phase transformation occurs in the $\beta$ phase during HCPEB. That is, $\alpha^{\prime}$ phase is confined within $\beta$, while nanocrystals are formed within $\beta$. The formation of nanocrystals is related to the rapid cooling of the surface of the matrix, and leads to the widening of $\beta$ diffraction peak (Figure 1) [3]. For pure titanium, only $\alpha^{\prime}$ phase exists on the surface of pure titanium after HCPEB (without $\beta$-Ti) $[27,28]$. In this paper, the addition of $\mathrm{Nb}$ prevents the transformation of $\beta-\alpha^{\prime}$ phase, so substantial $\beta$-Ti equiaxed grains were formed on the surface of $\mathrm{Nb}$-alloyed samples. This is the same as the result that element $C$ in austenite prevents martensite transformation in carbon steel irradiated by HCPEB [29]. Figure $5 \mathrm{~d}$ revealed that many fine particles with a size of about $10 \mathrm{~nm}$ were formed in the alloying layer, which are $\mathrm{NbTi}_{4}$ particles confirmed by SAED pattern. It further proved that $\mathrm{Nb}$ was dissolved into the TC4 alloy substrate surface after HCPEB irradiation. In fact, according to the literature [30], $\mathrm{NbTi}_{4}$ was observed in an amorphous phase after high-energy ball milling, The morphology of these particles is similar to the $\mathrm{NbTi}_{4}$ reinforced particles in this paper. In addition, Banerjee [31] said that $\mathrm{Cr}_{2} \mathrm{Ti}$ can be formed during the laser deposition of the Ti-Cr alloy, so $\mathrm{NbTi}_{4}$ is most likely to be formed during the rapid solidification of $\mathrm{HCPEB}$. In this paper, fine $\mathrm{NbTi}_{4}$ particles were formed in the $\mathrm{Nb}$-alloyed layer, but with the increase of the number of pulses, the new $\mathrm{Nb}$-alloyed layer continues to melt into the matrix, and part of $\mathrm{NbTi}_{4}$ particles will melt into the new $\mathrm{Nb}$-alloyed layer due to surface melting. For this reason, $\mathrm{Nb}$-rich regions will appear near $\mathrm{NbTi}_{4}$, which more easily forms equiaxed $\beta$ grains in the rapid solidification process, This is also why $\mathrm{NbTi}_{4}$ particles are found in $\beta$ grains. In addition, $\mathrm{NbTi}_{4}$ particles have the characteristics of dispersion distribution due to the thermal stress caused by HCPEB. 

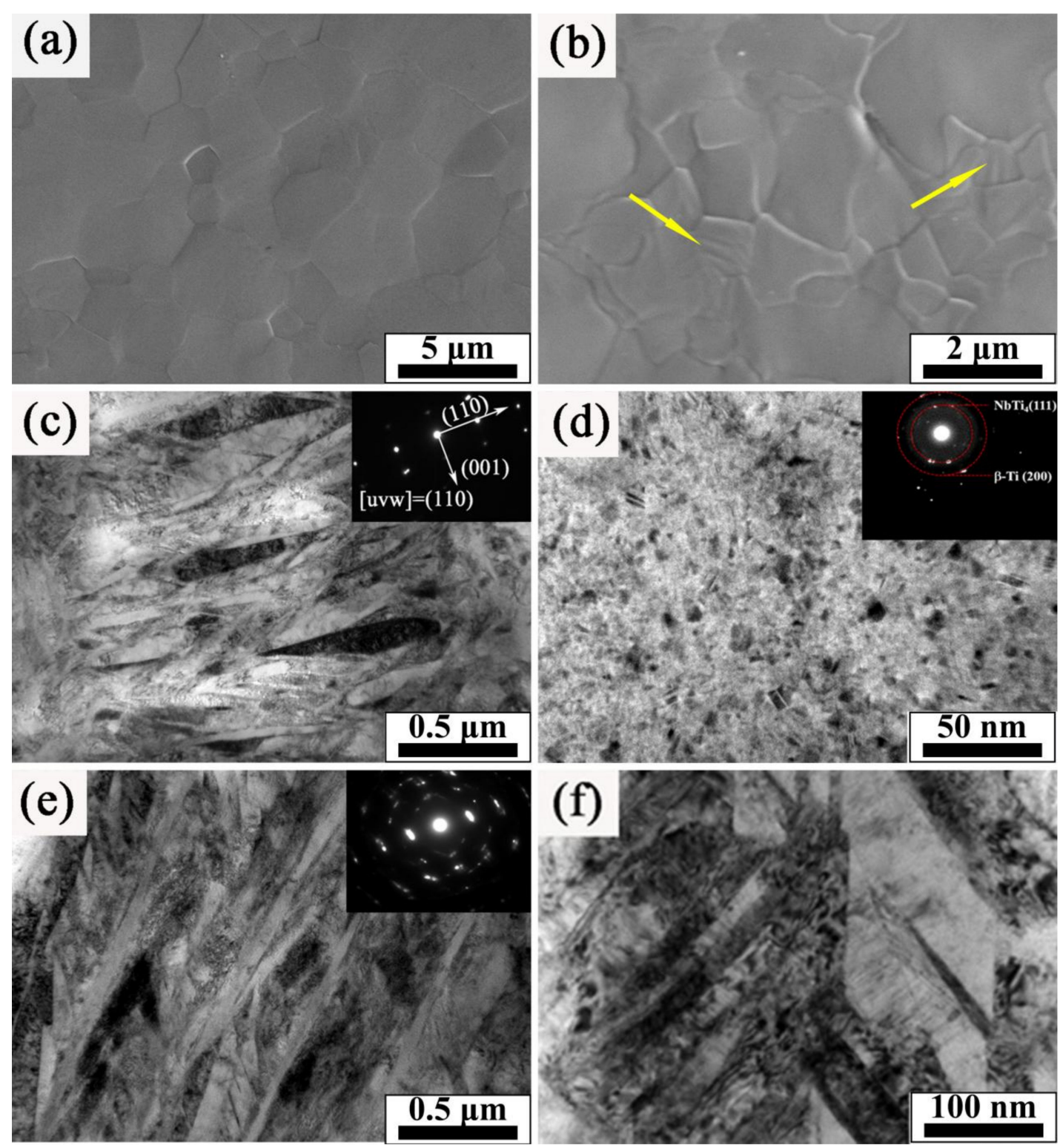

Figure 5. (a,b) SEM images, (c-f) TEM images and SAED patterns of the Nb-alloyed sample surface after 40-pulsed irradiation.

Figure 5e shows that many twin structures were formed in martensite $\alpha^{\prime}$ during HCPEB irradiation, and the diffraction spots appeared in pairs. The previous study shows that metal materials with hcp structure tend to form a twins structure during the deformation process, which is mainly due to the lack of sufficient slip system of the hcp structure, thus inducing twinned deformation and the forming a twin structure [32-34]. In addition, it was found that the plasticity of metal in the hexagonal system was closely related to the twin structure induced during deformation; the more types and quantities of twins, the better the plasticity of the material [33]. Another common structure in martensite $\alpha^{\prime}$ is the high-density dislocation; such a dislocation configuration and even the dislocation wall are often observed after strong plastic deformation of the material, as shown in Figure 5f. Under the action of strong external stress, the higher dislocation density will result in the formation of dislocation tangling. Subsequently, the dislocations were rearranged to form these dislocation walls $[35,36]$. The formation of a defects structure will have an important influence on the properties of materials such as strengthening. 


\subsection{Microhardness}

The surface microhardness of the initial and Nb-alloyed samples is shown in Figure 6. The hardness of the original sample was $320 \mathrm{HV}$. With increasing numbers of pulses, an increment of hardness was found for the $\mathrm{Nb}$-alloyed samples. After 40 pulses, the hardness of the sample rose to $361 \mathrm{HV}$, which was $12.8 \%$ higher than that of the original sample. According to the literature [37], a softened material has been obtained after HCPEB irradiation. The main reason is that HCPEB irradiation induced the formation of sole $\alpha^{\prime}$ phase, which is softer than the $\alpha$-Ti in TC4 alloy. Therefore, the reasons for the improved hardness for $\mathrm{Nb}$ alloyed samples has to analyzed.

(1). The temperature gradient of the cooling process was high after HCPEB irradiation, causing the rapid solidification of surface and thereby forming a fine uniform structure. Although the hardness of $\alpha^{\prime}$ generated by HCPEB irradiation is lower than that of $\alpha$ martensite, the size of $\alpha^{\prime}$ laths was found to be very tiny and accompanied by high density dislocation and twins.

(2). According to Guo's work [37], the main factor for increasing hardness should be the $\mathrm{Nb}$ solid solution strengthening. In this study, the $\mathrm{Nb}$ and matrix element diffused each other due to the deposition of the surface energy during irradiation, and it is suggested that the $\mathrm{Nb}$ atoms can act as obstacles for the dislocation motion. To illustrate, once the stress required to activate the dislocation increases, the yield increases, leading to a further increase in microhardness, known as solid solution strengthening.

(3). The enhancement of the $\beta$ phase and the presence of hardening $\mathrm{NbTi}_{4}$ phase played a significant role in dispersion strengthening, which is the key to improving the surface hardness of TC4- $\mathrm{Nb}$ alloyed samples. In addition, the HCPEB irradiated alloy layer formed an abundant deformation structure (twin crystals and dislocation), which could play the role of splitting martensite, further refining grain, strengthening dislocation and promoting the improvement of surface hardness $[5,38]$.

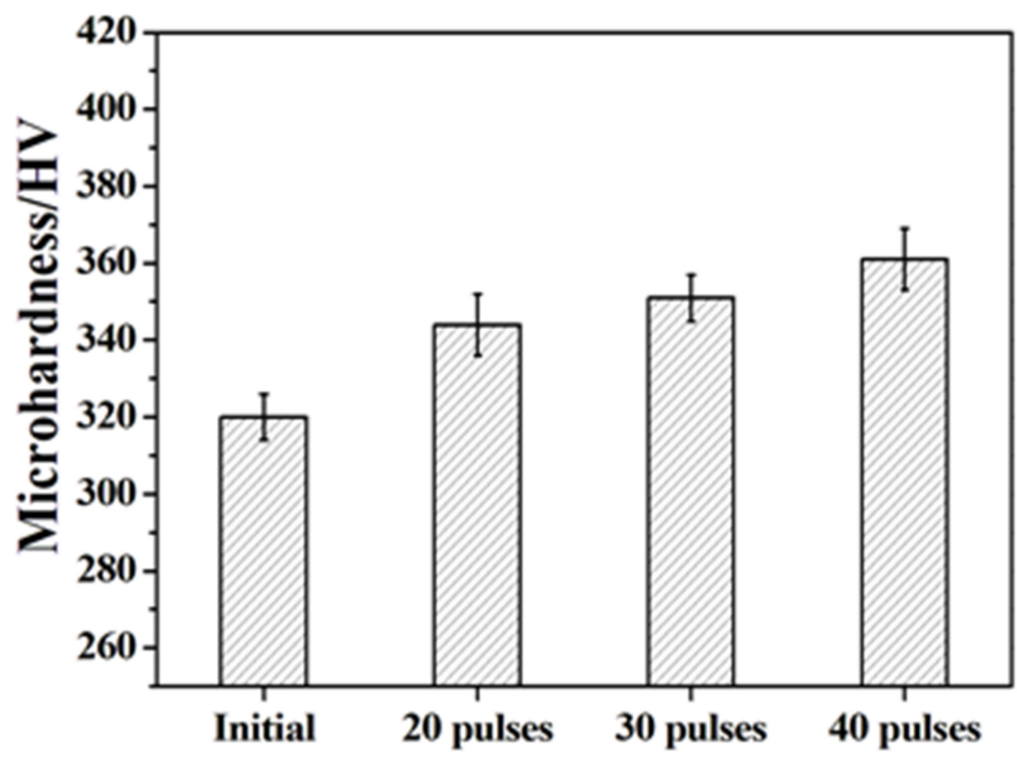

Figure 6. Microhardness measurement of initial and $\mathrm{Nb}$-alloyed samples.

\subsection{Wear Resistance}

Figure 7 shows the coefficient of friction (COF) and wear rate of initial TC4 and $\mathrm{Nb}-$ alloyed samples. Figure 7a demonstrates that the running-in stage of the initial sample is about three min, after which the friction coefficient is stable at 0.48 . The COF of $\mathrm{Nb}$-alloyed sample is significantly reduced, and the running-in stages are very short, followed by the stable wear stage. The $\mathrm{COF}$ values of $\mathrm{Nb}$-alloyed samples decrease gradually when the pulse number increases and reaches the lowest value after 40 pulses of irradiation, which is 
0.32. There is almost no obvious fluctuation in the sliding process, and the COF is relatively stable. The wear rate of $\mathrm{Nb}$-alloyed samples also decreases significantly (Figure $\mathrm{7b}$ ), and the relationship between wear rate value and irradiation number is consistent with the COF. In combination with Figure 7a,b, the abrasion resistance of the sample after 40-pulsed irradiation is relatively ideal.
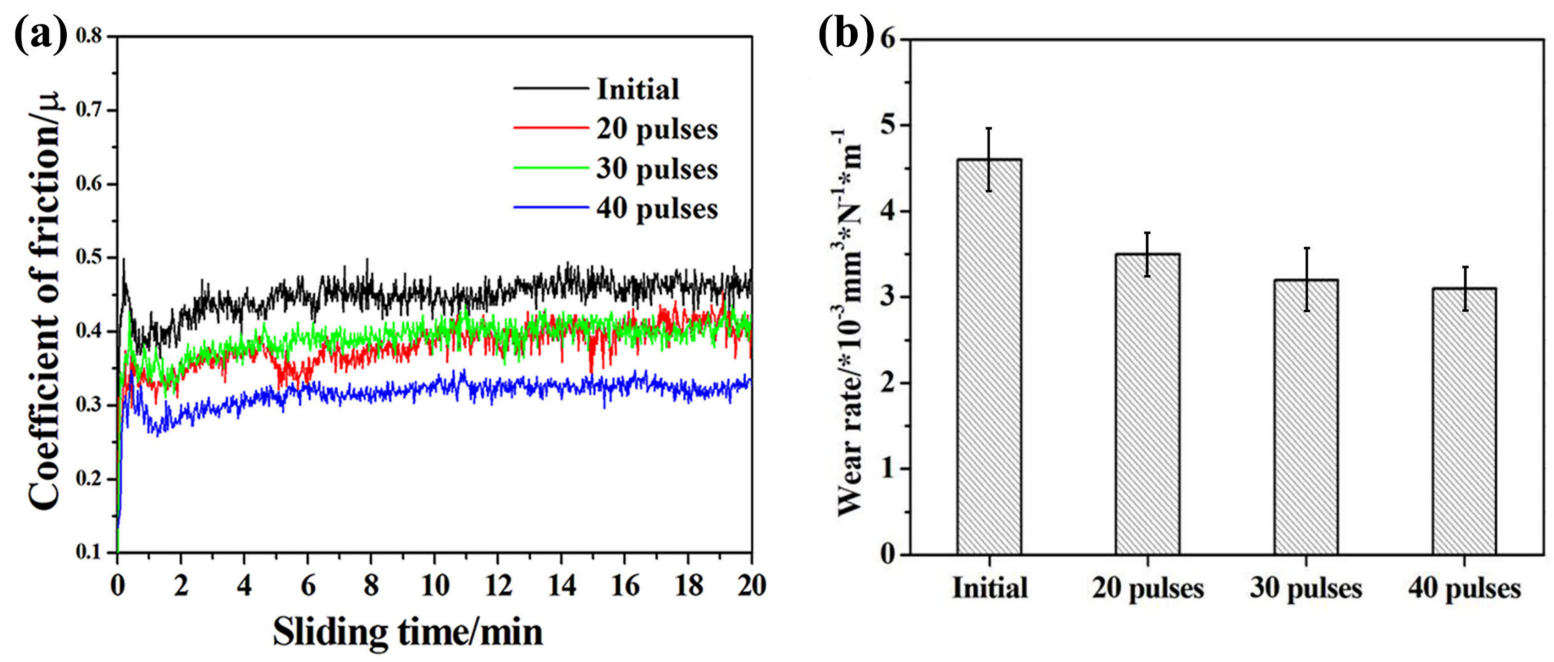

Figure 7. Tribological behavior of initial and Nb-alloyed samples. (a) Coefficient of friction; (b) Wear rate.

According to he previous study $[39,40]$, the wear mechanism of TC4 could be classified to Equation (1).

$$
W=\frac{L}{v H} \frac{\beta}{f^{2} \zeta c^{2} \rho_{0}^{2}}
$$

For the TC4 alloy, the hardness increases after irradiation, and the wear rate decreases because the abrasion resistance is proportional to hardness. The oxide formed during the dry sliding test of the original $\mathrm{TC} 4$ was $\mathrm{TiO}_{2}$. But more compact oxide was formed after irradiation, so the $f$ and $\rho_{0}$ of the irradiated samples were greater than those of the original TC4. In addition, $\beta$ might slightly increased because of the crystal defects and the greater grain boundary density [41].

Figure 8 shows the surface wear profile morphology of the initial and $\mathrm{Nb}$-alloyed samples. A wide wear scratch can be observed from the initial sample, and the wear trace width is about $697.3 \mu \mathrm{m}$ (Figure $8 \mathrm{a}$ ). From Figure $8 \mathrm{~b}-\mathrm{d}$, The width of the wear traces of the 20-pulsed, 30-pulsed, and 40-pulsed irradiation are $640 \mu \mathrm{m}, 634 \mu \mathrm{m}, 619 \mu \mathrm{m}$ respectively. The values of $\mathrm{Nb}$-alloyed samples are significantly lower than those of the original samples and show a downward trend when the irradiation pulses increased, which are consistent with the results of microhardness and wear resistance. Since the irradiated samples exhibit a lower friction coefficient and wear rate, the surface debris falls off less, which inhibits the damage caused by wear particles, and forms a relatively lower wear width during testing. This is further confirmation that the irradiated sample surface shows excellent tribological properties in the friction and wear test. The improvement in tribological behavior is mostly due to the fact that the $\mathrm{Nb}$-alloyed samples have better adhesion with the substrate than that of the initial samples [37], and the oxide layer formed on the surface of the irradiated sample during friction can also be used as a protective film or lubricant [42]. Therefore, the abrasion resistance of $\mathrm{Nb}$-alloyed samples is better than that of the initial TC4 alloy. 
(a)

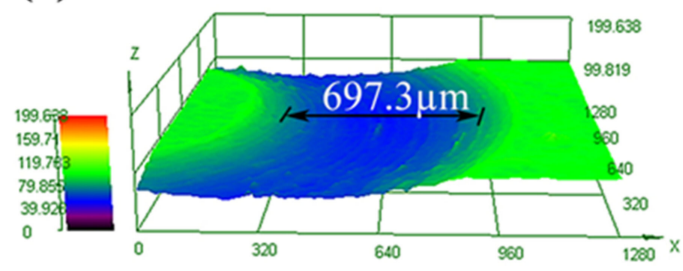

(c)

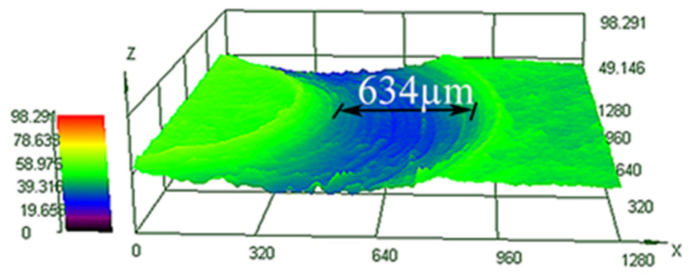

(b)

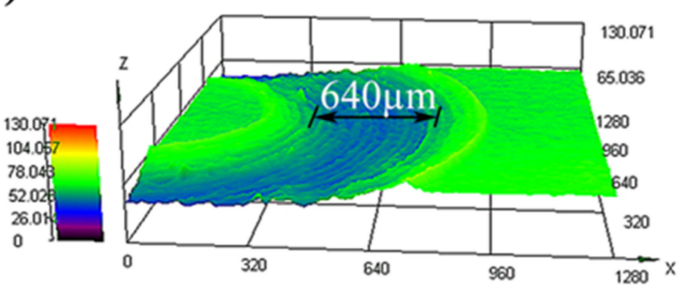

(d)

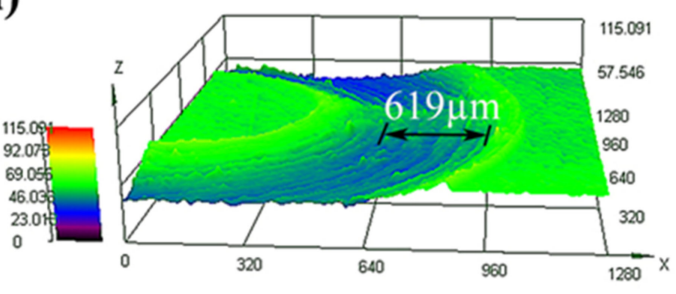

Figure 8. LSM pictures of initial and Nb-alloyed samples. (a) Initial; (b) 20 pulses; (c) 30 pulses; (d) 40 pulses.

\subsection{Corrosion Resistance}

The polarization curve, corrosion potential and current density statistics of initial and $\mathrm{Nb}$-alloyed samples in $3.5 \mathrm{wt} \% \mathrm{NaCl}$ solution are shown in Figure 9. From the electrochemical corrosion polarization curve in Figure 9a, the initial passivation area of the $\mathrm{Nb}$-alloyed samples is significantly large, indicating that the corrosion resistance has been improved after irradiation $[43,44]$. The current peak appeared in the second passivation area of the irradiated samples because of the continuous self-repair of the oxide film, which contributed to the improved corrosion properties [45].

(a)

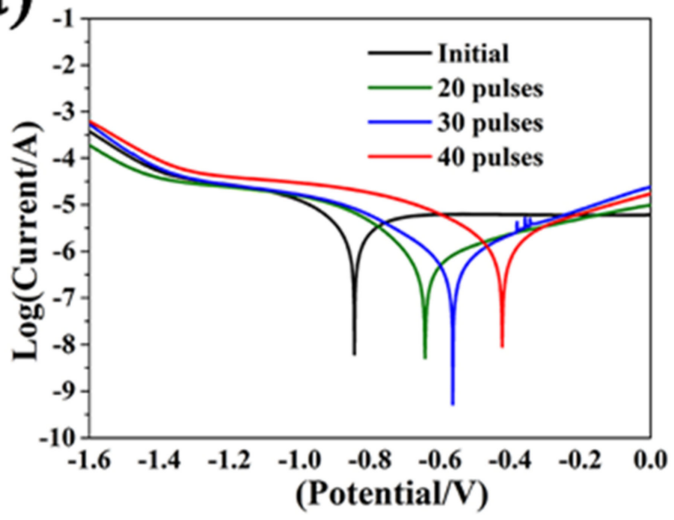

(b)

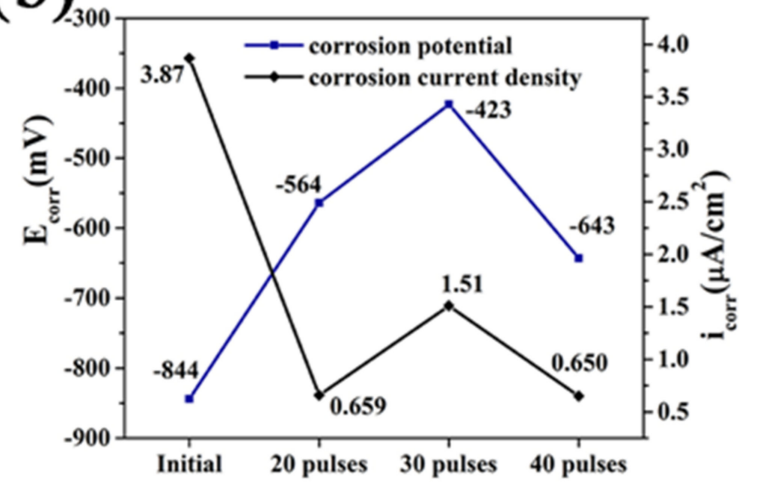

Figure 9. Corrosion performance of initial and irradiated samples in $3.5 \mathrm{wt}$ \% $\mathrm{NaCl}$ solution (a) Electrochemical corrosion polarization curve; (b) Corrosion potential (Ecorr) and corrosion current density (icorr).

Figure $9 \mathrm{~b}$ is the statistical diagram of corrosion potential $\left(\mathrm{E}_{\mathrm{corr}}\right)$ and corrosion current density ( $\left.\mathrm{i}_{\text {corr }}\right)$. The $\mathrm{E}_{\text {corr }}$ of the $\mathrm{Nb}$-alloyed samples was increased, and the most obvious increase was $421 \mathrm{mV}$ after 30-pulsed irradiation. It is difficult to judge the corrosion resistance from a single corrosion voltage because it only reflects the thermodynamic possibility and directivity of metal corrosion. Figure $9 \mathrm{~b}$ also shows the corrosion current density, which was significantly reduced after HCPEB irradiation. The $\mathrm{i}_{\text {corr }}$ decreased from $3.87 \mu \mathrm{A} / \mathrm{cm}^{2}$ to $0.659 \mu \mathrm{A} / \mathrm{cm}^{2}$ after 20-pulsed irradiation. The $i_{\text {corr }}$ of the 30 -pulsed ones is slightly higher, but much lower than that of the original samples, which is $1.51 \mu \mathrm{A} / \mathrm{cm}^{2}$. The corrosion current density reached the lowest value $\left(0.650 \mu \mathrm{A} / \mathrm{cm}^{2}\right)$ after 40 -pulsed irradiation, indicating that the anti-corrosion performance was improved. 
Figure 10 depicts the corrosion morphology and EDS analysis of initial and $\mathrm{Nb}$-alloyed samples. In Figure 10a, deep corrosion pits and clear edges were found on the initial TC4, implying a severe pitting corrosion, but few corrosion pits were seen on the $\mathrm{Nb}$-alloyed surface after 20, 30, and 40 pulses of irradiation, as observed in Figure 10b-d. With the increase of irradiation pulses, the number and size of corrosion pit are reduced. In addition, EDS analysis of 40-pulsed irradiation in Figure 10d shows that the main elements of the surface are $\mathrm{Ti}, \mathrm{Al}, \mathrm{Nb}$ and $\mathrm{O}$ elements, indicating that a uniform protective oxidation film $\left(\mathrm{Nb}_{2} \mathrm{O}_{5}\right)$ was formed, which acts as protection, reducing the possibilities of pitting corrosion. The reasons for the improvement of corrosion resistance are discussed as follows.

(1). The addition of $\mathrm{Nb}$ promotes the nucleation of $\mathrm{Nb}_{2} \mathrm{O}_{5}$ on the surface of the alloy. According to the literature $[46,47]$, when the oxides are formed in the corrosive medium, the oxides are embedded in the matrix of the alloy as independent clusters. When alloying elements are uniformly distributed in each component phase of the alloy, these oxide clusters can be uniformly distributed in the matrix of the alloy, thus forming a stable passivation film on the surface of the alloy, so that the alloy shows good corrosion resistance.

(2). The grains within the $\mathrm{Nb}$-alloyed layer were refined during the irradiation process. The high increase in the number of grain boundaries provided more channels for the rapid diffusion of atoms, which results in the formation of denser oxide film on the top layer of the sample. Moreover, the melting pit and the composition uniformity on the surface have important effects on the compactness of the oxide film [48].

(3). Phase transition of the irradiated sample surface will also affect the corrosion resistance. Previous research showed that the formation of martensite is helpful to improve the corrosion resistance of the samples [44,49]. To sum up, the improvement of surface corrosion performance of $\mathrm{Nb}$-alloyed samples is the combined effect of the above factors.

In addition, the corrosion performance varies with the number of pulses. This is because the number of craters decreases with the increase of the number of pulses (as shown in Figure 2), the channels invaded by $\mathrm{Cl}^{-}$are reduced to improve corrosion performance.
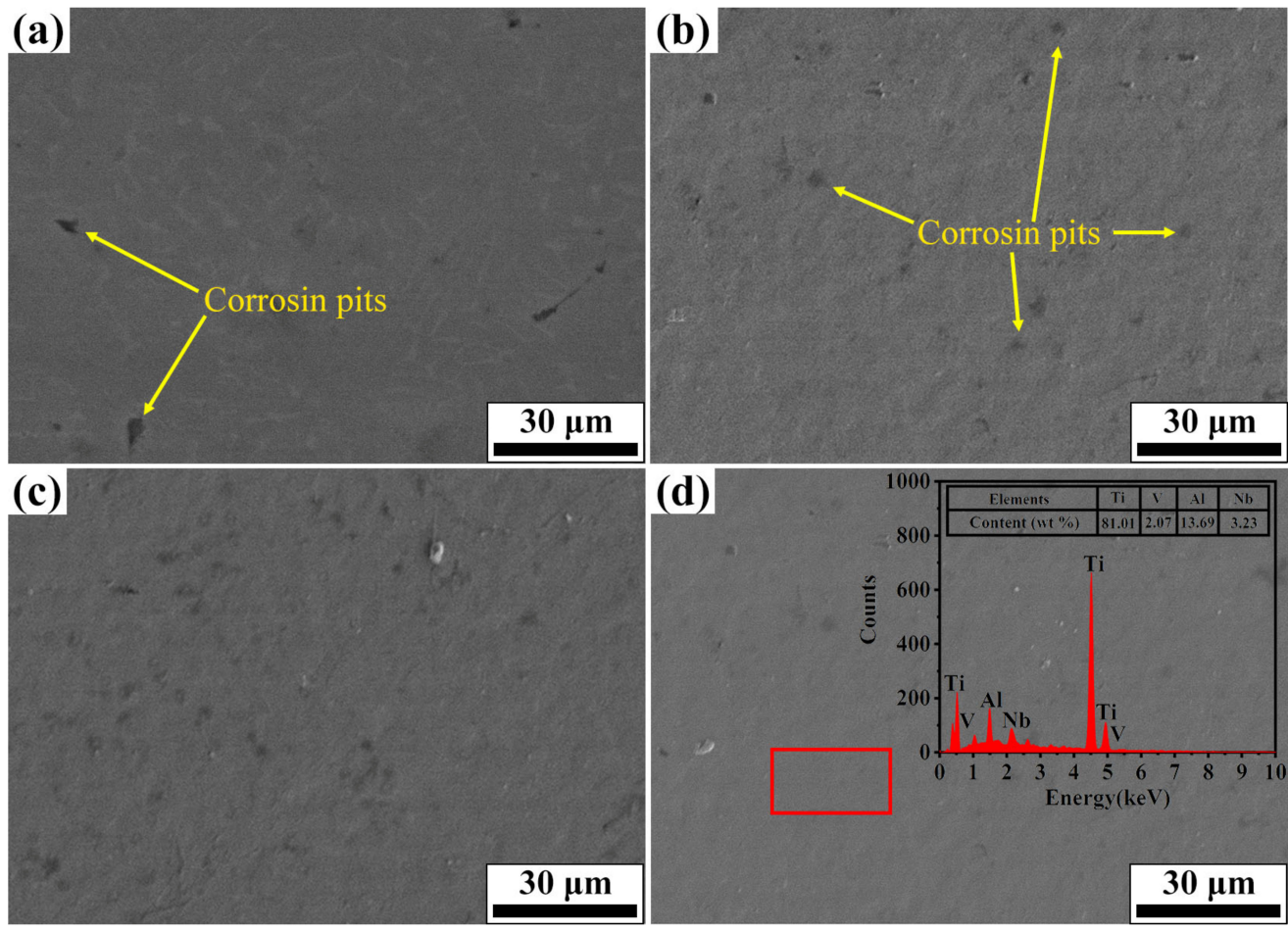

Figure 10. Corrosion morphology and EDS analysis of initial and Nb-alloyed samples. (a) Initial; (b) 20 pulses; (c) 30 pulses; (d) 40 pulses. 


\section{Conclusions}

In this paper, the $\mathrm{Nb}$ alloying layer was successfully prepared on the TC4 substrate by different pulses of HCPEB irradiation, and the surface performance was improved. The main conclusions are listed as follows:

(1). Extremely rapid heating, cooling and solidifying during HCPEB irradiation make $\mathrm{Nb}$ powder to dissolve into TC4 matrix and form an alloying layer on the surface of the TC4 alloy. A typical pit structure appeared on the surface layer, and the density and roughness of the pit decreased with the increase of irradiation pulses.

(2). Martensitic transformation occurred on the surface of TC4 alloy during HCPEB irradiation, forming a fine strip $\alpha^{\prime}$ martensite phase in some $\beta$ phase grains. Many $\mathrm{NbTi}_{4}$ particles with about $10 \mathrm{~nm}$ in size were formed in the $\beta$ phase.

(3). The microhardness and wear resistance of the sample surface were improved, which was mainly due to the joint action of several strengthening mechanisms such as solid solution strengthening, dispersion strengthening and fine crystal strengthening.

(4). The corrosion resistance of TC4-Nb alloys was significantly improved after irradiation, which is the result of $\mathrm{Nb}$ alloying, grain refining and surface homogenization.

Author Contributions: Conceptualization, X.D. and J.C.; methodology, X.D., J.C. and Q.G.; formal analysis, P.L.; investigation, N.T.; writing-original draft preparation, X.D.; writing-review and editing, N.T., C.Z. and Q.G.; visualization, N.T.; supervision, P.L.; project administration, Q.G.; funding acquisition, C.Z., J.C. and Q.G. All authors have read and agreed to the published version of the manuscript.

Funding: This research was funded by [Zhang Conglin] grant number [No. 52001273 and No. U1933124] and [Cai Jie] grant number [No. BK20201062].

Data Availability Statement: All data included in this study are available upon request by contact with the corresponding author.

Acknowledgments: This work was supported by National Natural Science Foundation of China (No. 52001273 and No. U1933124), the Jiangsu Province Natural Science Foundation for Youths (No. BK20201062).

Conflicts of Interest: The authors declare no conflict of interest.

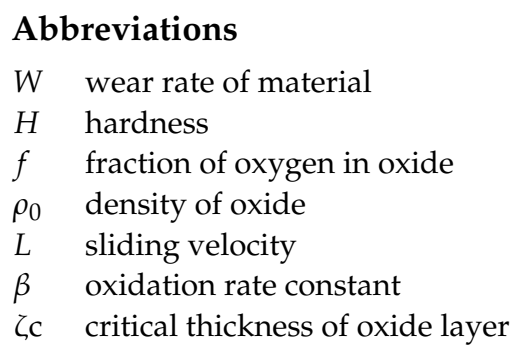

\section{References}

1. Yan, J.; Zhang, Z.; Xu, J.; Wu, Y.; Zhao, X.; Xue, Y.; Liu, H. Microstructure evolution of TC4 powder by spark plasma sintering after hot deformation. High Temp. Mater. Process. 2020, 39, 457-465. [CrossRef]

2. Gurrappa, I. Characterization of titanium alloy Ti-6Al-4V for chemical, marine and industrial applications. Mater. Charact. 2003, 51, 131-139. [CrossRef]

3. Zhang, L.; Peng, C.T.; Yao, X.; Guan, Q.; Lu, R. Surface alloying of Cr on Ti6Al4V alloy induced by high-current pulse electron beam. Surf. Coat. Technol. 2019, 370, 288-297. [CrossRef]

4. Yonekura, D.; Fujita, J.; Miki, K. Fatigue and wear properties of Ti-6Al-4V alloy with Cr/CrN multilayer coating. Surf. Coat. Technol. 2015, 275, 232-238. [CrossRef]

5. Yu, S.; Liu, D.; Cui, T.; Zhang, X. Formation process and cross-sectional hardness of a Cr-alloyed layer on Ti6Al4V alloy. Mater. Lett. 2015, 161, 724-726. [CrossRef]

6. Wang, Z.; Wu, H.; Lin, N.; Yao, X.; He, Z.; Liu, X. High-temperature tribological behaviors of TiNi/Ti2Ni alloyed layer on surface of Ti6Al4V alloy. Surf. Rev. Lett. 2017, 24, 1-7. [CrossRef]

7. Tang, C.; Liu, D.; Li, F. Plasma niobium alloying on Ti6Al4V alloy surface and its wear resistance. Heat Treat. Met. 2010, 35, 1-6. 
8. Qin, L.; Yang, K.; Liu, C.; Tang, B. Enhanced plasma boriding with molybdenum using double glow plasma surface alloying technique. Mater. Lett. 2012, 82, 127-129. [CrossRef]

9. Lyu, P.; Chen, Y.; Liu, Z.; Cai, J.; Zhang, C.; Jin, Y.; Guan, Q.; Zhao, N. Surface modification of CrFeCoNiMo high entropy alloy induced by high-current pulsed electron beam. Appl. Surf. Sci. 2020, 504, 144453. [CrossRef]

10. Ozur, G.E.; Proskurovsky, D.I.; Rotshtein, V.P. A mechanism of microcrater formation in metallic material irradiated by a low-energy high-current electron beam. Tech. Phys. Lett. 2016, 42, 328-331. [CrossRef]

11. Rotshtein, V.P.; Proskurovsky, D.I.; Ozur, G.E.; Ivanov, Y.F.; Markov, A.B. Surface modification and alloying of metallic materials with low-energy high-current electron beams. Surf. Coat. Technol. 2004, 180, 377-381. [CrossRef]

12. Zhang, C.; Lv, P.; Xia, H.; Yang, Z.; Konovalov, S.; Chen, X.; Guan, Q. The microstructure and properties of nanostructured Cr-Al alloying layer fabricated by high-current pulsed electron beam. Vacuum 2019, 167, 263-270. [CrossRef]

13. Jiang, W.; Wang, L.; Wang, X. Studies on surface topography and mechanical properties of TiN coating irradiated by high current pulsed electron beam. Nucl. Instrum. Methods Phys. Res. Sect. B Beam Interact. Mater. Atoms 2018, 436, 63-67. [CrossRef]

14. Rotshtein, V.P.; Ivanov, Y.F.; Markov, A.B.; Proskurovsky, D.I.; Karlik, K.V.; Oskomov, K.V.; Uglov, B.V.; Kuleshov, A.K.; Novitskaya, M.V.; Dub, S.N.; et al. Surface alloying of stainless steel 316 with copper using pulsed electron-beam melting of film-substrate system. Surf. Coat. Technol. 2006, 200, 6378-6383. [CrossRef]

15. Zhang, L.; Peng, C.T.; Guan, J.; Lv, P.; Guan, Q.; Lu, R. Nanocrystalline Cr-Ni alloying layer induced by high-current pulsed electron beam. Nanomaterials 2019, 9, 74. [CrossRef] [PubMed]

16. Yang, S.; Guo, Z.; Zhao, L.; Guan, Q.; Zhao, L.; Liu, Y. Microstructures and corrosion resistance of Zircaloy-4 after surface alloying with copper by high-current pulsed electron beam. Appl. Surf. Sci. 2020, 501, 144222. [CrossRef]

17. Proskurovsky, D.I.; Rotshtein, V.P.; Ozur, G.E.; Markov, A.B.; Nazarov, D.S.; Shulov, V.A.; Ivanov, Y.F.; Buchheit, R.G. Pulsed electron-beam technology for surface modification of metallic materials. J. Vac. Sci. Technol. A Vacuum Surf. Films 1998, 16, 2480-2488. [CrossRef]

18. Liang, W.p.; Miao, Q.; Ben, N.j.; Ren, B.l. Tribological behaviors of Ti-6Al-4V alloy with surface plasma molybdenized layer. Surf. Coat. Technol. 2013, 228, S249-S253. [CrossRef]

19. Zou, J.X.; Zhang, K.M.; Hao, S.Z.; Dong, C.; Grosdidier, T. Mechanisms of hardening, wear and corrosion improvement of 316 L stainless steel by low energy high current pulsed electron beam surface treatment. Thin Solid Films 2010, 519, 1404-1415. [CrossRef]

20. Zhang, C.; Cai, J.; Lv, P.; Zhang, Y.; Xia, H.; Guan, Q. Surface microstructure and properties of Cu-C powder metallurgical alloy induced by high-current pulsed electron beam. J. Alloy. Compd. 2017, 697, 96-103. [CrossRef]

21. Qin, Y.; Dong, C.; Wang, X.; Hao, S.; Wu, A.; Zou, J.; Liu, Y. Temperature profile and crater formation induced in high-current pulsed electron beam processing. J. Vac. Sci. Technol. A Vacuum Surf. Films 2003, 21, 1934-1938. [CrossRef]

22. Zhang, C.; Gao, Q.; Lv, P.; Cai, J.; Peng, C.T.; Jin, Y.; Guan, Q. Surface modification of Cu-W powder metallurgical alloy induced by high-current pulsed electron beam. Powder Technol. 2018, 325, 340-346. [CrossRef]

23. Kim, J.; Park, H.W. Influence of a large pulsed electron beam (LPEB) on the corrosion resistance of Ti-6Al-7Nb alloys. Corros. Sci. 2015, 90, 153-160. [CrossRef]

24. Meisner, L.L.; Semin, V.O.; Mironov, Y.P.; Meisner, S.N.; D'yachenko, F.A. Cross-sectional analysis of the graded microstructure and residual stress distribution in a TiNi alloy treated with low energy high-current pulsed electron beam. Mater. Today Commun. 2018, 17, 169-179. [CrossRef]

25. Grosdidier, T.; Philippe, M.J. Deformation induced martensite and superelasticity in a $\beta$-metastable titanium alloy. Mater. Sci. Eng. A 2000, 291, 218-223. [CrossRef]

26. Ghosh, C.; Basu, J.; Ramachandran, D.; Mohandas, E. Phase separation and $\omega$ transformation in binary V-Ti and ternary V-Ti-Cr alloys. Acta Mater. 2016, 121, 310-324. [CrossRef]

27. Cai, J.; Wan, M.; Zou, Y.; Lv, P.; Han, Z.; Wang, Z.; Guan, Q. Surface modification of pure titanium by high current pulsed electron beam. Adv. Mater. Res. 2012, 560, 994-999. [CrossRef]

28. Zhang, X.D.; Hao, S.Z.; Li, X.N.; Dong, C.; Grosdidier, T. Surface modification of pure titanium by pulsed electron beam. Appl. Surf. Sci. 2011, 257, 5899-5902. [CrossRef]

29. Zhang, L.; Jin, Y.; Wang, X.; Cai, J.; Guan, Q. Surface alloys of 0.45 C carbon steel produced by high current pulsed electron beam. High Temp. Mater. Process. 2019, 38, 444-451. [CrossRef]

30. Salvo, C.; Aguilar, C.; Cardoso-Gil, R.; Medina, A.; Bejar, L.; Mangalaraja, R.V. Study on the microstructural evolution of Ti-Nb based alloy obtained by high-energy ball milling. J. Alloy. Compd. 2017, 720, 254-263. [CrossRef]

31. Banerjee, R.; Collins, P.C.; Fraser, H.L. Phase evolution in laser-deposited titanium-chromium alloys. Metal. Mater. Trans. A 2002, 33, 2129-2138. [CrossRef]

32. Xian, W.H.; Li, D.G.; Chen, D.R. Investigation on ultrasonic cavitation erosion of TiMo and TiNb alloys in sulfuric acid solution. Ultrason. Sonochem. 2020, 62, 104877. [CrossRef] [PubMed]

33. Yoo, M.H.; Lee, J.K. Deformation twinning in h.c.p. metals and alloys. Philos. Mag. A Phys. Condens. Matter Struct. Defects Mech. Prop. 1991, 63, 987-1000. [CrossRef]

34. Zhang, L.; Han, Y. Twins formation and their role in nanostructuring of zirconium. Mater. Sci. Eng. A 2009, 523, 130-133. [CrossRef] 
35. Neiman, A.A.; Semin, V.O.; Meisner, L.L.; Ostapenko, M.G. Structural decomposition and phase changes in TiNi surface layer modified by low-energy high-current pulsed electron beam. J. Alloy. Compd. 2019, 803, 721-729. [CrossRef]

36. Dong, S.; Zhang, C.; Zhang, L.; Cai, J.; Lv, P.; Jin, Y.; Guan, Q. Microstructure and properties of Cu-Cr powder metallurgical alloy induced by high-current pulsed electron beam. J. Alloy. Compd. 2018, 755, 251-256. [CrossRef]

37. Guo, G.; Tang, G.; Ma, X.; Sun, M.; Ozur, G.E. Effect of high current pulsed electron beam irradiation on wear and corrosion resistance of Ti6Al4V. Surf. Coat. Technol. 2013, 229, 140-145. [CrossRef]

38. Cai, J.; Lv, P.; Zhang, C.L.; Wu, J.; Li, C.; Guan, Q.F. Microstructure and properties of low carbon steel after surface alloying induced by high current pulsed electron beam. Nucl. Instrum. Methods Phys. Res. Sect. B Beam Interact. Mater. Atoms 2017, 410, 47-52. [CrossRef]

39. Straffelini, G.; Molinari, A. Dry sliding wear of Ti-6Al-4V alloy as influenced by the counterface and sliding conditions. Wear 1999, 236, 328-338. [CrossRef]

40. Molinari, A.; Straffelini, G.; Tesi, B.; Bacci, T. Dry sliding wear mechanisms of the Ti6A14V alloy. Wear 1997, 208, 105-112. [CrossRef]

41. Krupp, U.; Christ, H.J. Internal nitridation of nickel-base alloys. Part, I. Behavior of binary and ternary alloys of the Ni-Cr-Al-Ti system. Oxid. Met. 1999, 52, 277-298. [CrossRef]

42. Ren, F.; Zhu, W.; Chu, K.; Zhao, C. Tribological and corrosion behaviors of bulk Cu-W nanocomposites fabricated by mechanical alloying and warm pressing. J. Alloy. Compd. 2016, 676, 164-172. [CrossRef]

43. Wu, P.P.; Deng, K.K.; Nie, K.B.; Zhang, Z.Z. Corrosion resistance of AZ91 Mg alloy modified by high-current pulsed electron beam. Acta Metall. Sin. Eng. Lett. 2019, 32, 218-226. [CrossRef]

44. Hao, S.; Wang, H.; Zhao, L. Surface modification of 40CrNiMo7 steel with high current pulsed electron beam treatment. Nucl. Instrum. Methods Phys. Res. Sect. B Beam Interact. Mater. Atoms 2016, 368, 81-85. [CrossRef]

45. Zhang, K.; Zou, J.; Grosdidier, T.; Dong, C.; Yang, D. Improved pitting corrosion resistance of AISI 316L stainless steel treated by high current pulsed electron beam. Surf. Coat. Technol. 2006, 201, 1393-1400. [CrossRef]

46. Morant, C.; López, M.F.; Gutiérrez, A.; Jiménez, J.A. AFM and SEM characterization of non-toxic vanadium-free Ti alloys used as biomaterials. Appl. Surf. Sci. 2003, 220, 79-87. [CrossRef]

47. Lv, P.; Xu, J.; Yang, R.; Zhang, C.; Zhang, F.; Dong, S.; Guan, Q. Effect of thermocycling on the microstructure of Ti-6Al-4V alloy in simulated low Earth orbit space environment. Sci. China Mater. 2016, 59, 363-370. [CrossRef]

48. Cai, J.; Gao, C.; Lv, P.; Zhang, C.; Guan, Q.; Lu, J.; Xu, X. Hot corrosion behaviour of thermally sprayed CoCrAlY coating irradiated by high-current pulsed electron beam. J. Alloy. Compd. 2019, 784, 1221-1233. [CrossRef]

49. Yan, P.; Zou, J.; Zhang, C.; Grosdidier, T. Surface modifications of a cold rolled $2024 \mathrm{Al}$ alloy by high current pulsed electron beams. Appl. Surf. Sci. 2020, 504, 144382. [CrossRef] 